\title{
Practice of Acute and Maintenance Electroconvulsive Therapy in the Psychiatric Clinic of a University Hospital from Turkey: between 2007 and 2013
}

\author{
Melike Ceyhan Balci Sengul, Ayse Nur Inci Kenar, Ezgi Hanci, İbrahim Sendur, Cem Sengul, Hasan Herken \\ Department of Psychiatry, School of Medicine, Pamukkale University, Denizli, Turkey
}

\begin{abstract}
Objective: Electroconvulsive therapy (ECT) can be given as the form of acute, continuation or maintenance ECT according to the process of administration. We report our 7 years' observation with acute and maintenance ECT in a university hospital in Turkey.

Methods: The medical records of the hospitalized patients treated with acute or maintenance ECT between the years 2007 and 2013 was retrospectively analyzed. The sociodemographic characteristics, diagnosis, data of ECT and the co-administered psychotropic drugs were recorded. The frequency of ECT was calculated by identifying the total number of the hospitalized patients during the study period from the hospital records.

Results: A total number of 1,432 female and 1,141 male patients hospitalized in a period of 7 years, with a total number of 111 patients treated with ECT. The ratio of ECT was 4\%, maintenance/acute ECT 11\%. For acute ECT, affective disorders (65.3\%) and psychotic disorders (21.6\%) were among the leading diagnoses. Maintenance ECT, the diagnosis was; 6 affective disorders, 4 psychotic disorders and 1 obsessive compulsive disorder. There was a significant difference between the patients receiving acute and maintenance ECT in terms of age, duration of illness, and number of previous hospitalizations and ECTs.

Conclusion: The percentage of patients treated with acute ECT is lower in our institution than that in many other institutions from our country. Acute and maintenance ECT should be considered as an important treatment option particularly for patients with long disease duration, a high number of hospitalizations and a history of benefiting from previous ECTs.
\end{abstract}

KEY WORDS: Electroconvulsive therapy; Maintenance electroconvulsive therapy; Electroconvulsive therapy indications.

\section{INTRODUCTION}

Electroconvulsive therapy (ECT) is an effective and safe somatic treatment method that is in use for more than 70 years in psychiatry in the treatment of severe mental disorders through inducing generalized epileptic seizure by performing an electrical stimulus to the patients' cranium, usually through two electrodes. The primary indications for ECT use are various psychiatric and neurological disorders including psychotic depression, suicide risk, treatment-resistant mania, schizophrenia, schizoaffective disorder, catatonic states due to organic causes, delirium and neuroleptic malignant syndrome. ${ }^{1-3)}$

Variable results have been reported from different countries in regard to the prevalence of ECT use. The rate

\footnotetext{
Received: March 16, 2015 / Revised: June 22, 2015

Accepted: August 6, 2015

Address for correspondence: Ayse Nur Inci Kenar, MD

Department of Psychiatry, School of Medicine, Pamukkale University, 20070, Denizli, Turkey

Tel: +90-258-4440728, Fax: +90-258-2131034

E-mail: drinci79@hotmail.com
}

of the ECT use can easily be calculated in some developed countries like United States, United Kingdom, and Australia, where central databases exist. But unfortunately the developing countries like Turkey don't have central statistical collection of data about the treatments. ${ }^{4,5)}$ Turkish studies on the prevalence of ECT usage has been reported between $9-16 \%$ in hospitalized patients. ${ }^{4,6)}$ If we compare the results, the ones from our country are higher than those from United States and also European countries as well as some of the Asia- Pacific countries. ${ }^{5)}$ The reason why they are contradictory can be due to collecting data from multi-centers. Also if we consider the amount of the samples and the regions where they were collected they may not represent the whole sample rate in general population of Turkey. ${ }^{7)}$ ECT should be performed with anesthesia since 2006 in Turkey. Till then ECTs were better documented and number of centers using ECT as a treatment method were on the rise. Only few centers were using maintenance ECT method in Turkey and details of this method might help other clinicians whom want to use this procedure. Unluckily there are lim-

(c) This is an Open-Access article distributed under the terms of the Creative Commons Attribution Non-Commercial License (http://creativecommons.org/licenses/by-nc/4.0) which permits unrestricted non-commercial use, distribution, and reproduction in any medium, provided the original work is properly cited. 
ited numbers of studies in the literature on maintenance ECT, and also most of them are in the form of case reports or review of the case reports. ${ }^{1,8)}$

In this article we aimed to present sociodemographic and clinical characteristics of patients for acute and maintenance ECT, and to compare the differences between patients treated with acute and maintenance ECT.

\section{METHODS}

\section{Study Design}

Study was conducted in Psychiatry Clinic of Pamukkale University Hospital in Turkey. Our clinic was a part of general hospital with 26 beds. The sociodemographic characteristics, diagnoses of patients, number of ECT sessions, the stimulus intensity per session, seizure duration per session, symptoms, complications, clinical response to ECT, number and length of hospitalizations, and the co-administered psychotropic drugs during the study period were filled out from the patients' medical records retrospectively, from 2007 to 2013 . The study was approved by the institutional ethics committee (2014-02). All the patients were diagnosed according to the Diagnostic and Statistical Manual of Mental Disorders-fourth edition (DSM-IV) criteria. ECT choice was preferred mainly for the patients who had no response to pharmacotherapy, and for the patients who needed rapid improvement because of life-threatening symptoms (such as suicide, catatonia) and also for the patients who had previously experienced ECT, requested the treatment voluntarily. For treated population rate, a person was counted only once, irrespective of the number of ECT administrations. The parameters of number of ECT sessions, stimulus intensity per session and seizure duration per session for 11 patients treated with maintenance ECT were not included in the analysis. The patients receiving maintenance ECT were recorded only once and in the year the treatment had begun. The response of the patient to ECT was calculated by the daily observation notes filled by the physician and nurse as well as by the analysis of the scores on Clinical Global Impression Scale (CGI) were applied before and after hospitalization.

\section{Electroconvulsive Therapy}

ECT was initiated in our department in 2007 and ECT procedures had been performed in the operating room under general anesthesia. All ECTs were performed with anesthesia in our clinic and anesthesia processes was conducted by anesthesiologists. Our institution is the only medical center having an ECT unit in a city of one million inhabitants with also serving the patients referred for ECT from other institutions.

ECT is administered by a team including a psychiatry resident and nurse and an anesthesia resident and technician. Prior to the application of ECT, all patients or families must sign informed consent with an explanation of the details of the treatment and the anesthesia, as well as the anticipated benefits and risks. Before administration of ECT, routine laboratory studies including complete blood count, blood chemistry, thyroid function test, B12 and folate levels, electrocardiography (ECG), posteroanterior chest X-ray and electroencephalography (EEG) are performed. All the patients who are planned to have ECT routinely receive consultation by the physicians from internal medicine and anesthesia departments. If these departments give the patients approval for ECT, anesthetic drug administration are instructed to fast for 12 hours before the procedure. Psychotropic drugs such as benzodiazepines and mood stabilizers, which may alter seizure threshold significantly, are terminated 12 hours before the application. However, patients are allowed to continue the typical and atypical antipsychotic drugs, selective serotonin reuptake inhibitors and serotonin-norepinephrine reuptake inhibitors drugs. Prior to the administration of ECT, $0.5-1 \mathrm{mg}$ of intravenous atropine is given to the patients in order to reduce the salivation and to prevent increases in the heart rate. While pentothal or propofol is being used as anesthetic agent, succinylcholine is used for muscle relaxation. Their doses are adjusted by the anesthesiologist. Patients are continuously oxygenated during the procedure, ECG, heart rate and blood pressure is monitored and recorded before and after the procedure and the anesthetic agent, complications (if developed) and the stimulus intensity and seizure duration are routinely recorded on the ECT monitoring form. A brief-pulse square-wave ECT device (Thymatron system DGX device; Somatics, Inc., Lake Bluff, IL, USA) is used in all ECT procedures.

Electrical stimulus intensity is determined by using the dose titration method. When the minimum level producing an acceptable seizure is established, it is increased to the upper grade. The EEG output on the instrument is used in order to monitor if the seizures occur during the ECT procedure and intravenous midazolam is immediately given if the seizure lasts more than 120 seconds. Bilateral-bitemporal ECT is used in our department and the acute ECT is administered thrice a week (on Monday, Wednesday and Friday) for a total of 7-12 sessions with 
the number of sessions are decreased or increased by the clinical response of the patient. In our clinic, continuation type of ECT can also be given to the patients after following a course of acute ECT for up to 6 months in order to prevent the relapse. The maintenance ECT is given following the continuation ECT and used to prevent the recurrence. Although there is not a consensus on the frequency of the maintenance therapy, most of the practitioners use flexible and individually scheduled weekly/biweekly/monthly courses.

\section{Statistical Analysis}

In statistical analysis, descriptive analysis of the data was performed by using SPSS version 17 software (SPSS, Inc., Chicago, IL, USA). Quantitative variables were expressed as mean \pm standard deviation and categorical variables were given as numbers and percentages. Chi-square test was used to compare the categorical variables. Continuous variables were compared by using Mann Whitney $U$-test. $p$ $<0.05$ was considered as statistically significant.

\section{RESULTS}

There were a total of 1,432 female and 1,141 male patients hospitalized between 2007 and 2013 (female/male ratio $1.25: 1)$. During the study period, a total of 111 patients (100 acute and 11 maintenance ECTs) were treated with ECT ( $4 \%$ of the hospitalized patients). The incidence of ECT per year were: $1.78 \%, 2.04 \%, 5.2 \%, 7.9 \%, 5.2 \%$, $3.9 \%$ and $4.2 \%$, respectively (from 2007 to 2013 ).

\section{Sociodemographic Characteristics of Patients}

Of the patients $59(53.2 \%)$ were male and $52(46.8 \%)$ were female (male/female ratio 1.31:1). Between the years 2007 and 2013, 3.6\% of the female hospitalized patients and $5.1 \%$ of the male hospitalized patients were treated by ECT. There was no pregnant woman among the ECT-treated female patients. The mean age of the patients was $40.3+$ 14.2 years (range, 18-78 years). With regard to the marital,

Table 1. The diagnosis in electroconvulsive therapy-treated patients

\begin{tabular}{lclr}
\hline \multicolumn{1}{c}{ Diagnosis } & Patient & Age (yr) & Session \\
\hline Unipolar major depression & $47(42.3)$ & $46.6 \pm 15.2$ & $7.4 \pm 2.8$ \\
Bipolar depression & $9(8.1)$ & $38.3 \pm 10.7$ & $8.7 \pm 1.7$ \\
Schizophrenia & $17(15.3)$ & $32.2 \pm 9.2$ & $7.3 \pm 3.7$ \\
Bipolar manic episodes & $17(15.3)$ & $31.2 \pm 11.4$ & $7.9 \pm 1.9$ \\
Schizoaffective disorder & $7(6.3)$ & $40.4 \pm 6.3$ & $7.57 \pm 1.5$ \\
Obsessive-compulsive disorder & $8(7.2)$ & $41.4 \pm 14.6$ & $7.5 \pm 1.8$ \\
Catatonia & $1(0.9)$ & $18.0 \pm 0.0$ & $8.0 \pm 0.0$ \\
Others & $4(3.6)$ & & \\
\hline
\end{tabular}

Values are presented as number (\%) or mean \pm standard deviation. education, employment status of the ECT-treated patients, 65 (58.6\%) were married, 37 (33.3\%) were housewife, 45 $(40.5 \%)$ were in primary school. Fifty-eight $(52.2 \%)$ patients were no medical co-morbidities. Sixty-two patients $(55.9 \%)$ were referred from outpatient clinic.

\section{Diagnosis of Patients}

With regard to the diagnostic distribution of the patients, $47(42.3 \%)$ had unipolar major depression, the mean age was $46.6 \pm 15.1$ years and the number of mean session was $7.4 \pm 2.8$ for depressive patients. The other diagnostic groups, the mean age and the number of session in ECT-treated patients were given in Table 1.

\section{Data Related to ECT}

Of the ECT-treated patients, 80 (72.1\%) did not receive ECT previously, while 5 (4.5\%) had one and 26 (23.4\%) had two courses of ECT previously. The mean disease duration for all patients treated with ECT was 117.8 \pm 104.4 months (range, 1-528 months), the mean number of hospitalizations was $3.3 \pm 2.8$ (range, 1-14), the mean number of ECT sessions was 7.6 \pm 2.6 (range, 2-18).

With regard to the mean number of sessions until the response to treatment, $84.0 \%$ of the patients responded in session 7 or later, $37.0 \%$ responded within the first 3 sessions and $2.8 \%$ responded in session $3-6$, while $9.3 \%$ had an inadequate response.

The mean length of hospitalization was $27.4 \pm 12.4$ days (range, 7-82 days). The most common complaint was headache in $10(9.0 \%)$, myalgia in $3(2.7 \%)$ and amnesia in $4(3.6 \%)$ patients. The rate of complications was found to be $0.3 \%$ with being anterograde amnesia in 1 , prolonged seizure in 3, apnea in 1, and arrhythmia in 1 patient.

For all sessions, mean stimulus intensity was $71.5 \pm 14.1$

Table 2. Data related to electroconvulsive therapy (ECT)

\begin{tabular}{lc}
\hline \multicolumn{1}{c}{ Variable } & Data \\
\hline Receive ECT previously & \\
No & $80(72.1)$ \\
One course & $5(4.5)$ \\
Two courses & $26(23.4)$ \\
Complaints & \\
No & $94(84.7)$ \\
Headache & $10(9)$ \\
Myalgia & $3(2.7)$ \\
Amnesia & $4(3.6)$ \\
Sessions & $7.6 \pm 2.6(2-12)$ \\
Stimulus intensity (joule) & $71.5 \pm 14.1(65-103)$ \\
Duration of seizures (sec) & $26.1 \pm 11.2(23-45)$ \\
\hline
\end{tabular}

Values are presented as number (\%) or mean \pm standard deviation (range). 
Table 3. The psychotropic drugs used in addition to electroconvulsive therapy

\begin{tabular}{lc}
\hline \multicolumn{1}{c}{ Drug } & Number (\%) \\
\hline One psychotropic drug & $33(29.7)$ \\
Two psychotropic drugs & $46(41.4)$ \\
Three or more psychotropic drugs & $32(28.8)$ \\
Antidepressants & \\
Venlafaxine & $27(24.3)$ \\
Mirtazapine & $7(6.3)$ \\
Milnacipran & $5(4.5)$ \\
Fluoxetine & $5(4.5)$ \\
Paroxetine & $5(4.5)$ \\
Sertraline & $4(3.6)$ \\
Bupropione & $4(3.6)$ \\
Duloxetine & $4(3.6)$ \\
Clomipramine & $4(3.6)$ \\
Fluvoxamine & $2(1.8)$ \\
Antipsychotics & \\
Quetiapine & $49(44.1)$ \\
Olanzapine & $35(31.5)$ \\
Aripirazole & $18(16.2)$ \\
Risperidone & $11(9.9)$ \\
Amilsulpride & $10(9.0)$ \\
Paliperidone & $7(6.3)$ \\
Flupentixol & $4(3.6)$ \\
Zuklopentixol & $2(1.8)$ \\
Clozapine & $1(0.9)$ \\
Haloperidol & $1(0.9)$ \\
Clorpromazine & $1(0.9)$ \\
\hline
\end{tabular}

joules and mean duration of the seizures was $26.1+11.2$ seconds (Table 2).

\section{Psychotropic Drugs Used with ECT}

Of the patients, 33 (29.7\%) were using one, 46 (41.4\%) were using two and $32(28.8 \%)$ were using three or more psychotropic drugs in addition to ECT. Of the patients under antidepressant drug therapy, 27 (24.3\%) were using venlafaxine, under antipsychotic drug therapy, 49 (44.4\%) were using quetiapine. One other catatonic patient was using benzodiazepine (Table 3).

\section{Maintenance ECT}

A total of 11 patients received maintenance ECT, for which the mean duration of maintenance ECT was 13.8 months (range, 8-46 months). Of these 11 patients, 2 were still on the maintenance ECT at time of writing of this paper. The diagnosis was unipolar depression in 4, bipolar depression in 1, schizophrenia in 2, obsessive-compulsive disorder (OCD) in 1, bipolar manic episodes in 1 and schizoaffective disorder in 2 of 11 patients receiving maintenance ECT.

There was a significant difference between the patients receiving maintenance and acute ECT in terms of age, duration of illness, and number of previous hospitalizations
Table 4. Comparison of patients treated with acute and maintenance electroconvulsive therapy (ECT)

\begin{tabular}{lccl}
\hline \multicolumn{1}{c}{ Variable } & $\begin{array}{c}\text { Maintenance } \\
\text { ECT }\end{array}$ & $\begin{array}{c}\text { Acute } \\
\text { ECT }\end{array}$ & $p$ value* \\
\hline Patient $(n)$ & 11 & 100 & \\
Age (yr) & $53.9 \pm 9.5$ & $38.8 \pm 13.9$ & $0.01^{\dagger}$ \\
Number of hospitalizations & $3.1 \pm 2.5$ & $5.0 \pm 4.1$ & 0.37 \\
Receive ECT previously & $0.6 \pm 1.2$ & $2.4 \pm 1.2$ & $0.00^{\dagger}$ \\
Duration of illness (mo) & $101.9 \pm 96.1$ & $201.5 \pm 114.9$ & $0.02^{\dagger}$ \\
\hline
\end{tabular}

Values are presented as number only or mean \pm standard deviation. *Mann Whitney U test was performed. ${ }^{\dagger} p<0.05$.

and ECTs. The mean age was $53.9 \pm 9.5$ vs. $38.8 \pm 13.9$ years, the mean duration of illness was $101.9 \pm 96.1$ vs. $201.5 \pm 114.9$ months, the mean number of previous hospitalizations was $3.1 \pm 2.5$ vs. $5.0 \pm 4.1$ and number of previous ECTs was $0.6 \pm 1.2$ vs. $2.4 \pm 1.2$ in patients treated with acute and maintenance ECT, respectively $(p<0.01)$ (Table 4).

\section{DISCUSSION}

In the present study, the ECT rate among the inpatients of our psychiatry clinic during the survey period was $4 \%$. Previous retrospective naturalistic studies in Turkey reported rates ranging from $2.2 \%$ and $16.4 \%$. ${ }^{4}$ Our results show that the rate of ECT usage is higher than the rates in the Western countries, but it is lower than the certain Africa and Asia countries. ${ }^{5,9)}$ However, this ratio does not show the prevalence of ECT use in the general psychiatric population in Turkey. All the results of data collected from Turkey are higher than the rate we found in the present study. The literature suggests there is a wide variation in choosing ECT practice in countries and even between the regions within a country. These differences may be attributed to the differences in prejudices and legislations about ECT, technical staff and equipment, available number of hospital beds, the site of providing service, the institutions the studies had been conducted and the time periods studied. The rate of ECT use might be underestimated in the present study due to the facts that it covers a long study period of 7 years, there is no closed psychiatric clinic in the institution, low number of beds, it has been conducted in a smaller city and the healthcare providers in this institution may have different approaches to ECT.

According to the results of present study, ECT is most commonly used in patients with major depression, followed by those with schizophrenia and manic episode. In the 15-year study of Saatcioglu and Tomruk, ${ }^{4)}$ the most common indication for ECT was bipolar depression, followed by schizophrenia and major depression in Turkey. 
On the other hand, the most common indication for ECT were schizophrenia in an Hungarian and Asian study, affective disorders (unipolar or bipolar depression) in patients from US, Australia, New Zealand and Europe. 5,9-11) The present study had a total of 11 patients treated with maintenance ECT. Of these 11 patients, the diagnosis was unipolar depression in 4, bipolar depression in 1, bipolar manic episode in 1, schizophrenia in 2, schizoaffective disorder in 2 and OCD in 1 patient. Thus, more than half of the maintenance ECT-treated patients had an affective disorder. Accordingly, there are some previous studies reporting the higher use and effectiveness of maintenance ECT in affective disorders, especially the depression. ${ }^{1,12,13)}$ There are only anecdotal reports of individual with maintenance ECT in pharmacotherapy refractory OCD (comorbid schizoaffective disorder or bipolar disorder). ${ }^{14,15)}$ Our case was not comorbid any psychiatric disorder, he was pharmacotherapy refractory OCD, showing a reduction of OCD symptoms with 18 months of maintenance ECT. Although the primary diagnosis for ECT is major depression in some studies and psychotic disorders in others, ECT is considered as an important treatment option for the relief of symptoms in patients with major depression, bipolar disorder and psychotic disorders.

Although maintenance ECT is less used compared to the acute ECT, recent studies have provided more information about maintenance ECT. However, there is no consensus on the frequency of ECT sessions. ${ }^{1,8)}$ Although it can be individualized, maintenance ECT is usually given weekly in the first 4-6 months, biweekly for the subsequent 4-6 months and monthly thereafter in our department. Maintenance ECT lasted for a mean duration of 13.8 months (range, 8-46 months). Of these 11 patients, 2 were still continued to receive maintenance ECT at the time of writing this paper. Controversy also exists on the duration of maintenance ECT. It is usually determined individually according to the side effects and the response to treatment. A comprehensive review have reported that the time periods for the duration of ECT varied up to 7 years and that vast majority of cases used co-medications. ${ }^{1)}$ Accordingly, all maintenance ECT-treated patients were receiving psychotropic drugs in the present study.

The patients treated with maintenance ECT were older and had longer disease duration, a higher number of hospitalizations and a higher number of previous ECTs compared to those treated with acute ECT. It should be kept in mind that continuation and maintenance ECT are effective treatment options particularly in patients who had benefited previously from the acute ECT.
The mean number of ECT sessions was $7.57 \pm 2.59$ for all acute ECTs. There was no difference between the diagnostic groups in terms of the number of sessions. Although it can be individualized, ECT is usually given for 6-12 sessions. ${ }^{6,16,17)}$ The mean duration of hospitalization was $27.43 \pm 12.43$ days, with no significant difference between the diagnostic groups. This is similar to that of Balikci et al. ${ }^{6}$ and is lower than that of Canbek et al., ${ }^{16)}$ which may be related with the rapid process of decision-making and preparation for ECT in our institution.

The mean duration of seizures was $26.14 \pm 11.23 \mathrm{sec}-$ onds for all sessions. An adequate seizure should last at least in 25 seconds. Although the duration of seizures is an inadequate parameter for assessing the effectiveness of ECT, convulsions lasting less than 15 seconds and seizure activity on EEG lasting less than 25 seconds are considered to indicate the ineffectiveness of ECT. ${ }^{2,6,16)}$

The mean stimulus intensity was $71.53 \pm 14.12$ joules. It is well known that electrical stimulus parameters are important in terms of effectiveness and side effects of ECT. It should be used at the lowest dose possible to achieve response to treatment. ${ }^{18,19)}$

Similar to the previous studies, most patients in our study showed a clinical improvement and remission or a complete remission according to DSM-IV criteria for the severity and the course modifiers. ${ }^{4,5)}$ Remission was also defined as the state in which patients can lead a somewhat social life. Of the patients, $84 \%$ responded to the treatment at session 7 or later, thus it was concluded that the patient should not be considered as unresponsive unless 8 sessions have been completed. Some previous have reported an earlier response to the therapy. ${ }^{16)}$ However, it is a major limitation of the present study that evaluation of the response to the therapy was based on CGI (CGI is a global index and not specific rating scale for diagnosis) and observation notes of the physicians and nurses.

The most common side effect was headache, memory problems and muscle pain. In particular, previous studies have commonly reported subjective memory impairment and pain in ECT-treated patients. ${ }^{4,5)}$ Although nearly half of the patients had co-morbidities including diabetes mellitus, hypertension and thyroid diseases, the rate of complications was only $0.3 \%$ in the present study, with being anterograde amnesia in 1, prolonged seizure in 3, apnea in 1 and arrhythmia in 1 patient. There was no serious complication necessitating the termination of ECT. It is possible that because all ECT procedures are modified and all patients are examined in detail before the procedure, risk of complication has reduced. 
Of the patients, 33 (29.7\%) were using one, 46 (41.4\%) were using two and $32(28.8 \%)$ were using three or more psychotropic drugs in addition to ECT, with the number of drugs used is being not correlated with the duration of seizures. To our knowledge, there are no previous studies on the relationship between the co-medications and ECT. Most commonly used drugs were venlafaxine (24.3\%) among the antidepressant drugs and quetiapine (44.1\%), followed by olanzapine (31.5\%) and aripiprazole (16.2\%) among the antipsychotic drugs. Although there are some previous case reports on the development of bradycardia and asystole with ECT use in patients receiving venlafaxine, some authors have suggested that the drug can be safely used with ECT. ${ }^{12,13,20,21)}$ However, only one of our cases used venlafaxine has developed arrhythmia. There are a few studies on the simultaneous use of antipsychotic drugs with ECT, with most of them are being in the form of case reports and patient series or open follow-up studies. ${ }^{22-24)}$ The present study found no relationship between drug use and seizure duration or rate of complications.

According to the results of the present study, maintenance ECT should be considered particularly in patients with a longer duration of hospitalization, with a high number of hospitalization and who had benefited previously from ECT. However, it is the major limitations of the present study that it is a retrospective study of medical records, our findings might not be generalized to Turkey and that there was a great number of acute ECT and limited number maintenance ECT groups. Moreover, adequate clinical data was not available and any scale except for CGI was not used for the specific assessment of diagnosis treatment response. Nevertheless, present study has some advantages including covering a long period of evaluation of 7 years (between the years 2007 and 2013), involving the patients treated with maintenance ECT, including a standard form (ECT monitoring form) consisting of the diagnosis, stimulus intensity, seizure duration, symptoms and complications, evaluating the concomitant use of psychotropic drugs and response the treatment. The results of the present study may be used to communicate about the importance of more standard and thoughtful ECT monitoring forms across the entire country for a better data collection and for an improved oversight. Reconsideration of the ECT procedures by the institutions may contribute to the systematic education of the psychiatry residents on ECT.

\section{REFERENCES}

1. Petrides G, Tobias KG, Kellner CH, Rudorfer MV. Continuation and maintenance electroconvulsive therapy for mood disorders: review of the literature. Neuropsycho- biology 2011;64:129-140.

2. Tomruk NB, Kutlar MT, Menges OO, Canbek O, Soysal H. Electroconvulsive therapy use handbook. Istanbul:Ece matbabacilik;2007.

3. Fink M. Convulsive therapy: a review of the first 55 years. $J$ Affect Disord 2001;63:1-15.

4. Saatcioglu O, Tomruk NB. Practice of electroconvulsive therapy at the research and training hospital in Turkey. Soc Psychiatry Psychiatr Epidemiol 2008;43:673-677.

5. Leiknes KA, Jarosh-von Schweder L, Høie B. Contemporary use and practice of electroconvulsive therapy worldwide. Brain Behav 2012;2:283-344.

6. Balikci A, Bolu A, Akarsu S, Kocak N, Erdem M, Aydemir $\mathrm{E}$, et al. Practice of electroconvulsive therapy between the years of 2006-2011 at a university hospital in Turkey. Anatol J Psychiatr 2013;14:340-346.

7. Bilgi MM, Eker C, Gonul AS. Maintenance electroconvulsive therapy. Curr Approach Psychiatr 2010;2:421-442.

8. Martínez-Amorós E, Cardoner N, Gálvez V, Urretavizcaya M. Effectiveness and pattern of use of continuation and maintenance electroconvulsive therapy. Rev Psiquiatr Salud Ment 2012;5:241-253.

9. Gazdag G, Takács R, Tolna J, Iványi Z, Ungvari GS, Bitter I. Electroconvulsive therapy in a Hungarian academic centre (1999-2010). Psychiatr Danub 2013;25:366-370.

10. Chanpattana W, Kramer BA, Kunigiri G, Gangadhar BN, Kitphati R, Andrade C. A survey of the practice of electroconvulsive therapy in Asia. J ECT 2010;26:5-10.

11. Alvarez-Grandi S, de la Barra SL, Seifert A, Glue P. Electroconvulsive therapy use in Otago, New Zealand: a 10-year retrospective audit of patient-level treatment data. Aust N Z J Psychiatry 2014;48:548-553.

12. Bernardo M, Navarro V, Salvà J, Arrufat FJ, Baeza I. Seizure activity and safety in combined treatment with venlafaxine and ECT: a pilot study. J ECT 2000;16:38-42.

13. Dilbaz N, Sengül C, Okay T, Bayam G, Türkoglu A. The combined treatment of venlafaxine and ECT in treatmentresistant depressive patients. Int $J$ Psychiatry Clin Pract 2005;9:55-59.

14. Elias A, Chathanchirayil SJ, Bhat R, Prudic J. Maintenance electroconvulsive therapy up to 12 years. J Affect Disord 2014; 156:228-231.

15. Kockaya MH, Savas HA, Selek S. Four depression cases treated with maintenance electroconvulsive therapy (ECT). Bull Clin Psychopharmacol 2008;18:113-118.

16. Canbek O, Menges OO, Atagun MI, Kutlar MT, Kurt E. Report on 3 years' experience in electroconvulsive therapy in bakirkoy research and training hospital for psychiatric and neurological diseases: 2008-2010. J ECT 2013;29:51-57.

17. Stevens A, Fischer A, Bartels M, Buchkremer G. Electroconvulsive therapy: a review on indications, methods, risks and medication. Eur Psychiatry 1996;11:165-174.

18. Andrade C. Electrical parameters and the efficacy of ECT: pulse frequency or stimulus train duration? J ECT 2012;28: 142; author reply 142-143.

19. Sackeim HA, Prudic J, Nobler MS, Fitzsimons L, Lisanby $\mathrm{SH}$, Payne $\mathrm{N}$, et al. Effects of pulse width and electrode placement on the efficacy and cognitive effects of electroconvulsive therapy. Brain Stimul 2008;1:71-83.

20. Kranaster L, Janke C, Hausner L, Frölich L, Sartorius A. Venlafaxin-associated post-ictal asystole during electroconvulsive therapy. Pharmacopsychiatry 2012;45:122-124.

21. Lyons JE, Symon J. Asystole during electroconvulsive therapy in an elderly woman treated concomitantly with venlafaxine. Aust N Z J Psychiatry 2008;42:255. 
22. Palm U, Forsthoff A, de la Fontaine L, Rupprecht T, Karch $\mathrm{S}$, Meisenzahl EM, et al. Electroconvulsive therapy and corpus callosum aplasia: a case report. J ECT 2011;27:e17-e20.

23. Ravanić DB, Pantović MM, Milovanović DR, Dukić-Dejanović $\mathrm{S}$, Janjić V, Ignjatović DR, et al. Long-term efficacy of electroconvulsive therapy combined with different antipsychotic drugs in previously resistant schizophrenia. Psychiatr Danub 2009;21:179-186.

24. Tang WK, Ungvari GS. Efficacy of electroconvulsive therapy combined with antipsychotic medication in treatment-resistant schizophrenia: a prospective, open trial. J ECT 2002;18:90-94. 